\title{
Simple Model to Explain Effects of Plasma Protein Binding and Tissue Binding on Calculated Volumes of Distribution, Apparent Elimination Rate Constants and Clearances*
}

\author{
J. G. Wagner \\ College of Pharmacy and Upjohn Center for Clinical Pharmacology, \\ The University of Michigan, Ann Arbor, Michigan, USA
}

Received: March 26, 1976, accepted: June 10, 1976

Summary. A simple pharmacokinetic model, incorporating linear plasma protein binding, linear tissue binding, and first order elimination of free (unbound) drug, was studied. If $\mathrm{Cl}_{p}$ is the plasma clearance, $\mathrm{V}_{f}$ is the "true" volume of distribution of free drug, $\beta$ is the apparent elimination rate constant, $\sigma$ is the fraction of the drug which is free in plasma, $f$ is the fraction of the drug which is free in the entire body, $k_{f}$ is the intrinsic elimination rate constant for free drug, and $A_{T B}$ is the initial amount of drug which is bound to tissues, then the model indicates that the following relationships hold: (1) $C l_{p}=V_{f} \sigma k_{f} ;$ (2) $\beta=f k_{f}$; and $V_{\text {dext }}=(\sigma / f) V_{f}$. Only $\sigma$, and not $f$, can be measured experimentally. Dividing $C l_{p}$ by $\sigma$ provides an estimate of the intrinsic clearance of free drug, $v_{f} k_{f}$. A plot of Vdext versus $\sigma$ has an intercept equal to $V_{f}$, and the ratio of the slope/intercept is an estimate of $\mathrm{A}_{\mathrm{TB}} / \mathrm{A}_{\mathrm{f}}$, where $\mathrm{A}_{\mathrm{f}}$ is the initial amount of free drug (equal to $V_{f}$ times initial concentration of free drug in plasma). Thus, an estimate of $A_{T B}$ may be obtained. Dividing the intrinsic clearance by $V_{f}$ provides an estimate of $\mathrm{k}_{f}$. Thus, theoretically, estimates of $V_{f}, k_{f}, A_{T B}^{O}$ and $f$ may be obtained. The variables are not separated when $\beta$ is plotted versus $\sigma$, and curvature of such plots is expected; no useful information is obtained from such plots.

Key words: Plasma protein binding, tissue binding, volume of distribution of free drug, intrinsic rate constant for free drug, amount bound to tissues.

There has been much discussion in the literature on the effects of plasma protein binding on the distribution, elimination, and activity of drugs (Anton and Solomon, 1973; Benya and Wagner, 1975; Coffey, 1972; Garrett, 1972; Keen, 1972; Krüger-Thiemer, 1966 and 1968; Levy and Yacobi, 1974; Martin, 1965; Wagner, 1971 and 1975) and these citations are not intended to be complete. The review of keen (1971) not only discussed the

\footnotetext{
*Partly supported by Public Health Service Grant 5-P-11-GM 1559 and partiy by Grant 1RO1AAOO683O1Al from the National Institute on Alcohol Abuse and Alcoholism, Rockville, Maryland.
}

possible effects of plasma protein binding, but also discussed the possible effects of tissue binding. He cited data showing that cardiac glycosides which are highly bound to plasma proteins are also highly bound to tissues. A similar situation has been reported for diphenhydramine (Wagner, 1973 and Albert et al., 1975) and for warfarin in the rat (Benya and Wagner, 1975; Yacobi and Levy, 1975). Several authors (Coffey, 1972; Garrett, 1972; Keen, 1971; Krüger-Thiemer, 1966 and 1968; Levy and Yacobi, 1974; Martin, 1965; Yacobi and Levy, 1975) have developed mathematical and pharmacokinetic models and equations which incorporate plasma protein binding. Others (Disanto, 1971 and Wagner, 1971 and 1975) have developed models to illustrate possible ef- 
fects of tissue binding. Bischoff and Dedrick (1968) developed a flow ratelimited model, which incorporated both plasma protein binding and binding to several different types of tissues; they assumed that the relationship for binding to plasma proteins could also be used for tissue binding; equations used were those of the Langmuir type. Hermann (1975) showed that the binding of ouabain and digitoxin by human erythrocytes obeyed the Langmuir equation. When the dissociation constant is much greater than the drug concentration, the Langmuir equation collapses to a linear binding equation.

In inter-individual comparisons of a group of one species of animal or man it would be advantageous if one could predict, for example, the plasma clearance of a drug by measurement of the fraction of the drug which is free in plasma. The question arises as to which are the appropriate pharmacokinetic parameters to correlate with this fraction. The purpose of this report is to determine which relationship or relationships have a firm footing in pharmacokinetic theory, rather than the alternative approach of just making empirical correlations. The physical model approach also suggests when one might expect a trend line to be linear or curved; often, scatter in data, as a result of just biological variation and assay error, does not allow one to adequately determine when a trend line should be linear or curved.

\section{THEORETICAI}

Symbolism

Af - amount (moles) of free drug at time $t$

Af - initial amount (moles) of free drug at time zero.

$\mathrm{A}_{\mathrm{PB}}$ - amount (moles) of plasma protein bound drug at time $t$.

$\mathrm{APB}_{\mathrm{P}}$ - initial amount (moles) of plasma protein bound drug at time zero.

$\mathrm{A}_{\mathrm{TB}}$ - amount (moles) of tissue bound drug at time $t$.

$\mathrm{A}_{\mathrm{TB}}$ - initial amount (moles) of tissue bound drug at time zero.

B - apparent elimination rate constant, such that $-d$ ln $c_{p} / d t=\beta$

$\mathrm{Cl}_{\mathrm{p}}$ - plasma clearance (defined by equation 31).

$\mathrm{C}_{\mathrm{f}}$ - molar concentration of free (unbound) drug at time $t$.

$C_{f}^{O}$ - initial molar concentration of free (unbound) drug at time zero.

$\mathrm{C}_{\mathrm{p}}$ - molar total plasma concentration of drug (defined by equation 24) at time $t$.

$c_{p}^{O}$ - initial molar total plasma concentration of drug at time zero.

$\mathrm{C}_{\mathrm{PB}}$ - molar concentration of plasma protein bound drug at time $t$.
$\mathrm{C}_{\mathrm{TB}}-$ molar concentration of tissue bound drug at time $t$.

D - the dose of drug administered by bolus intravenous injection.

$f$ - the fraction of the total amount of drug in the body which is free. (defined by equation 14).

$k_{f}$ - the intrinsic elimination rate constant for free drug (dimension of $1 /$ time).

$\mathrm{K}_{\mathrm{P}}$ - the association constant for protein bound drug $\left(k_{P}=k_{1} / k_{2}\right)$.

$k_{T}$ - the association constant for tissue bound drug $\left(\mathrm{K}_{\mathrm{T}}=\mathrm{k}_{3} / \mathrm{k}_{4}\right)$.

$m$ - the number of binding sites for drug on tissue protein.

$n$ - the number of binding sites on plasma protein.

P - molar concentration of plasma protein.

$\sigma$ - the fraction of drug which is free in plasma (defined by equation 19).

$t$ - time.

$t^{\prime}$ - some specific time.

$t_{1}$ - a lag time needed in real life to establish model conditions.

$T$ - molar concentration of tissue which binds the drug.

varea - a volume of distribution defined by equation 34 .

Vdext - a volume of distribution defined by equation 39 .

$v_{f}$ - the "true" volume of distribution of free drug (dimension of liters).

$V_{T}$ - the volume of tissue which binds drug (liters).

Assumptions

1. When the dose, D, is given by bolus intravenous injection, the drug instantaneously is partitioned into three portions, namely $\mathrm{A}_{\mathrm{TB}}, \mathrm{A}_{\mathrm{PB}}$, and $\mathrm{A}_{\mathrm{f}}^{\circ}$.

2. Binding to both plasma protein and tissue is linear and independent of arug concentration.

3. The volume occupied by plasma proteins is ignored and hence $\mathrm{A}_{\mathrm{PB}}=\mathrm{V}_{\mathrm{f}} \mathrm{C}_{\mathrm{PB}}$ and $A_{f}=V_{f} C_{f}$.

4. The free drug is eliminated according to first order kinetics with rate constant equal to $\mathrm{k}_{\mathrm{f}}$.

5. Only free drug is available for elimination.

Model

The simple model includes only binding of drug to one class of sites on one plasma protein, binding of drug to one class of sites on one type of tissue and one fluid volume. However, the approach taken with the simple model could be readily extended to more complicated models as was done by Disanto (1971) and Wagner (1971) with analogous nonlinear models. The conclusions reached with the simple model would be extrapolatable to 
more complicated models of a similar type. The model is shown schematically in scheme 1 .

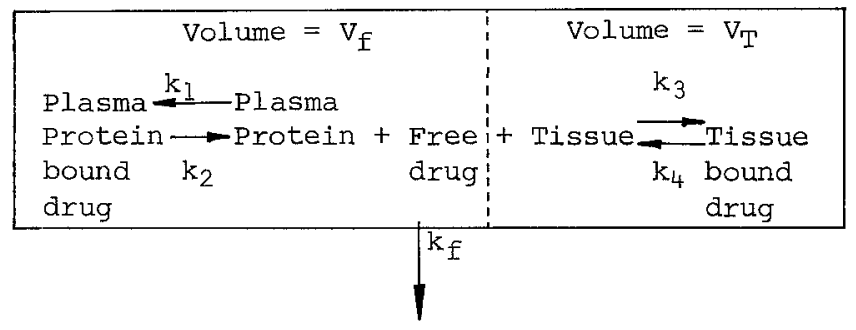

Scheme 1. Modified "one compartment open model" incorporating linear tissue binding and linear plasma protein binding

\section{Equations}

For linear binding:

$$
\begin{aligned}
& \mathrm{C}_{\mathrm{PB}}=\mathrm{n} \mathrm{K}_{\mathrm{P}} \mathrm{P} \quad \mathrm{C}_{\mathrm{f}} \\
& \mathrm{Eq} \cdot(1) \\
& \begin{aligned}
\mathrm{A}_{\mathrm{PB}} & =\mathrm{V}_{\mathrm{f}} \mathrm{C}_{\mathrm{PB}}=\mathrm{n} \quad \mathrm{K}_{\mathrm{P}} \quad \mathrm{P} \quad \mathrm{V}_{\mathrm{f}} \mathrm{C}_{\mathrm{f}} \\
& =\mathrm{nK}_{\mathrm{P}}
\end{aligned} \\
& \mathrm{C}_{\mathrm{TB}}=\mathrm{m} \mathrm{K}_{\mathrm{T}} \mathrm{T} \mathrm{C}_{\mathrm{f}} \\
& \mathrm{A}_{\mathrm{TB}}=\mathrm{V}_{\mathrm{T}} \mathrm{C}_{\mathrm{TB}}=\mathrm{m} \mathrm{K}_{\mathrm{T}} \mathrm{T} \quad \mathrm{V}_{\mathrm{T}} \mathrm{C}_{\mathrm{f}} \\
& =m k_{T} T_{\frac{T}{V_{f}}} A_{f} \\
& A_{f}=V_{f} C_{f} \\
& A_{f}+A_{P B}+A_{T B}+k_{f} \int_{0}^{t^{\prime}} A_{f} d t=D
\end{aligned}
$$

In equation 6 , the term containing the integral represents the amount of drug eliminated between time zero and time $t^{\prime}$.

Differentiation of equation 6 with respect to time yields equation 7 .

$$
\begin{aligned}
& \frac{d A_{f}}{d t}+\frac{d A_{P B}}{d t}+\frac{d A_{T B}}{d t}+k_{f} A_{f}=0 \mathrm{Eq} \cdot \\
& \text { Now, } \\
& \frac{d A_{P B}}{d t}=\frac{d A_{P B}}{d A_{f}} \cdot \frac{d A_{f}}{d t}=\left(\begin{array}{ll}
n & K_{P}
\end{array}\right) \frac{d A_{f}}{d t} \\
& \frac{d A_{T B}}{d t}=\frac{d A_{T B}}{d A_{f}} \cdot \frac{d A_{f}}{d t}=\left(m K_{T} T \frac{V_{T}}{V_{f}}\right) \frac{d A_{f}}{d t}
\end{aligned}
$$

Substituting from equations 8 and 9 into equation 7 yields:

$$
\frac{d A_{f}}{d t}\left[1+n K_{P}+m K_{T} T \frac{V_{T}}{V_{f}}\right]+k_{f} A_{f}=0
$$

Eq. (10)

Rearrangement of equation 10 gives equation 11 .

$$
-\frac{d A_{f}}{d t}=\left[\frac{k_{f}}{1+n K_{P} P+m K_{T} T \frac{V_{T}}{V_{f}}}\right] A_{f}
$$

$\mathrm{Eq} \cdot(11)$

Substituting from equation 5 for $A_{f}$ and cancelling the $V_{f}$ 's on both sides yields equation 12 from equation 11 .

$$
\begin{aligned}
-\frac{d C_{f}}{d t} & =\left[\frac{k_{f}}{1+n K_{P}+m K_{T} T \frac{V_{T}}{V_{f}}}\right] C_{f} \\
& =\beta C_{f}
\end{aligned}
$$

where $B$ is the apparent elimination rate constant and is given by equation 13 .

$$
B=\frac{k_{f}}{1+n K_{P} P+m K_{T} T \frac{V_{T}}{V_{f}}}
$$

$\mathrm{Eq} \cdot(13)$

If we define $f$ as the fraction of the total drug in the body which is free, then:

$$
f=\frac{A_{f}}{A_{f}+A_{P B}+A_{T B}}=\frac{1}{1+\frac{A_{P B}}{A_{f}}+\frac{A_{T B}}{A_{f}}}
$$

$\mathrm{Eq} \cdot(14)$

From equation 2 we obtain:

$$
\begin{aligned}
& \frac{A_{P B}}{A_{f}}=n K_{P} P \\
& \text { From equation } 4 \\
& \frac{A_{T B}}{A_{f}}=m K_{T} T \frac{V_{T}}{V_{f}}
\end{aligned}
$$$$
\text { From equation } 4 \text { we obtain: }
$$

Substituting from equations 15 and 16 into equation 14 gives equation 17 .

$$
\mathrm{f}=\frac{1}{1+\mathrm{n} \mathrm{K}_{\mathrm{P}} \mathrm{P}+\mathrm{m} \mathrm{K}_{\mathrm{T}} \mathrm{T} \frac{\mathrm{V}_{\mathrm{T}}}{\mathrm{V}_{\mathrm{f}}}}
$$

Substituting from equation 17 into equation 13 gives equation 18 .

$$
\beta=\mathrm{f} \mathrm{k}_{\mathrm{f}}
$$

Thus, according to this simple model, the apparent elimination rate constant, $\beta$, is a product of the intrinsic elimination rate constant for free drug, $\mathrm{k}_{\mathrm{f}}$, and the fraction of the total amount of drug in the body which is free, $f$.

If we define $\sigma$ as the fraction of the drug which is free (unbound) in the volume $V_{f}$ (and plasma is assumed to be representative of this fluid), then: 


$$
\begin{aligned}
\sigma & =\frac{C_{f}}{C_{f}+C_{P B}}=\frac{V_{f} C_{f}}{V_{f} C_{f}+V_{f} C_{P B}} \\
& =\frac{A_{f}}{A_{f}+A_{P B}}=\frac{1}{1+\frac{A_{P B}}{A_{f}}}
\end{aligned}
$$

Thus,

$$
1+\frac{A_{P B}}{A_{f}}=\frac{1}{\sigma}
$$

Substituting from equation 20 into equation 14 and rearranging gives:

$$
E=\frac{\sigma}{1+\left(\frac{A_{T B}}{A_{f}}\right) \sigma}
$$

Substituting for $f$ in equation 21 gives equation 22 .

$$
\beta=\left[\frac{\sigma}{1+\left(\frac{\mathrm{A}_{\mathrm{TB}}}{\mathrm{A}_{\mathrm{f}}}\right) \sigma}\right] \mathrm{k}_{\mathrm{f}}
$$

Equation 22 indicates that for interindividual comparisons of a drug in one species of animal or in man, a plot of the apparent elimination rate constant, $\beta$, versus the fraction of drug which is free in plasma, $\sigma$, will be gently curved over a small range of $\sigma$ values, even when the ratio $A_{T B} / A_{f}$ is constant from individual to individual of the species. With the scatter expected in such a plot (because of expected non-constancy of the $A_{T B} / A_{f}$ ratios) such curvature would be difficult to detect with real data.

Integration of equation 12 yields equation 23 .

$$
C_{f}=C_{I}^{O} e^{-\beta t}
$$

$\mathrm{Eq}$

The total plasma concentration, $C_{P}$, is given by equation 24 , after substituting from equation 1 for $\mathrm{C}_{\mathrm{PB}}$.

$$
\mathrm{c}_{\mathrm{P}}=\mathrm{C}_{\mathrm{f}}+\mathrm{C}_{\mathrm{PB}}=\left(1+\mathrm{n} \mathrm{K}_{\mathrm{P}} \mathrm{P}\right) \mathrm{c}_{\mathrm{f}}
$$

Multiplying both sides of equation 23 by $\left(1+n K_{P} P\right)$ and utilizing equation 24 gives equation 25 .

$$
C_{P}=\left(1+n K_{P} P\right) C_{ \pm}^{O} e^{-\beta t}=C_{P}^{O} e^{-\beta t}
$$

$\mathrm{Eq} \cdot(25)$

where

$$
\mathrm{C}_{\mathrm{P}}^{\mathrm{O}}=\left(1+\mathrm{n} \mathrm{K}_{\mathrm{P}} \mathrm{P}\right) \mathrm{C}_{\mathrm{f}}^{\mathrm{O}}
$$

Hence, the model predicts that the apparent elimination rate constant, $\beta$, obtained from total plasma concentrations is the same as that obtained from free drug concentrations.
The initial condition at time zero for the model is given by equation 27 .

$$
\mathrm{A}_{\mathrm{f}}^{\circ}+\mathrm{A}_{\mathrm{TB}}^{\circ}+\mathrm{A}_{\mathrm{PB}}^{\circ}=\mathrm{D} \quad \mathrm{Eq} \text {. }
$$

In equation $27, \mathrm{~A}_{\mathrm{f}}^{\mathrm{O}}, \mathrm{A}_{\mathrm{TB}}^{\mathrm{O}}$, and $\mathrm{A}_{\mathrm{PB}}^{\mathrm{O}}$ are the initial amounts existing as free drug, drug bound to tissues, and drug bound to plasma proteins, respectively, and $D$ is the dose administered. In real life it would take some finite time, even when the values of $k_{l}$ and $k_{3}$ are large, to attain this "initial condition", but this lag time, $t_{1}$, would most probably be small relative to the measured time courses of most drugs. The model assumes such partitioning, as indicated by equation 27, has already occurred at time zero. Hence, in real life the only difference would be that the $D$ in equation 27 would be replaced by $\mathrm{A} \mathrm{b}$, the apparent initial amount of drug in the body, such that $A_{b}^{O}<D$, and $t$ would be replaced by $\left(t-t_{1}\right)$.

An estimate would be

$$
\mathrm{A}_{\mathrm{b}}^{\mathrm{O}}=\mathrm{D}-\mathrm{V}_{\mathrm{f}} \mathrm{k}_{\mathrm{f}} \int_{0}^{t_{1}} \mathrm{C}_{\mathrm{f}} \mathrm{dt} \text {. }
$$

It may be readily seen that $C_{p}^{\circ}$ is also given by equation 28 .

$$
\mathrm{C}_{\mathrm{P}}^{\mathrm{O}}=\left[\frac{\mathrm{A}_{\mathrm{f}}^{O}+\mathrm{A}_{\mathrm{PB}}^{\circ}}{\mathrm{A}_{\mathrm{f}}^{O}+\mathrm{A}_{\mathrm{PB}}^{O}+\mathrm{A}_{\mathrm{TB}}^{O}}\right] \frac{\mathrm{D}}{\mathrm{V}_{\mathrm{f}}} \quad \mathrm{Eq} .
$$

Equations 14 and 19 also apply to the initial condition, as well as at any time $t$, hence substituting from those equations and cancelling the $A_{f}^{O}$ 's yields equation 29.

$$
\frac{\mathrm{f}}{\sigma}=\frac{\mathrm{A}_{\mathrm{I}}^{\circ}+\mathrm{A}_{\mathrm{PB}}^{\circ}}{\mathrm{A}_{\mathrm{f}}^{\circ}+\mathrm{A}_{\mathrm{PB}}^{O}+\mathrm{A}_{\mathrm{TB}}^{\circ}}
$$

Eq.

Substituting from equation 29 into equation 28 gives equation 30 .

$$
C_{\mathrm{P}}^{O}=\left(\frac{f}{\sigma}\right)\left(\frac{D}{V_{f}}\right)
$$

The plasma clearance, $\mathrm{Cl}_{\mathrm{P}}$, is usually calculated as the ratio of the dose to the total area under the total plasma concentration-time curve, as indicated by equation 31 .

$$
C l_{p}=\frac{D}{\int_{0}^{\infty} C_{p} d t}
$$

Integration of equation 25 between the limits of $t=0$ and $t=\infty$, followed by substitution for $C_{p}^{\circ}$ from equation 30 , substitution for $B$ from equation 18 and cancellation of the f's gives equation 32 .

$$
\int_{0}^{\infty} C_{p} d t=\frac{C_{p}^{O}}{\beta}=\frac{D}{V_{f} \sigma k_{f}} \quad E q .
$$


Substituting for the integral in equation 31 from equation 32 and cancellation of the D's yields equation 33 .

$$
\mathrm{Cl} l_{\mathrm{p}}=\mathrm{V}_{\mathrm{f}} \sigma \mathrm{k}_{\mathrm{f}}
$$

Thus, according to the model, the calculated plasma clearance, $\mathrm{Cl}_{p}$, is the product of the intrinsic clearance of free $d r u g, V_{f} k_{f}$, and the fraction of the drug which is free in plasma, o. For inter-individual comparisons a plot of $\mathrm{Cl}_{\mathrm{p}}$ versus $\sigma$ should yield a straight line, passing through the origin, with slope equal to $V_{f} k_{f}$, providing that the intrinsic clearance of free drug is constant from one individual to the next. Alternatively, and preferred, the plasma clearance of each individual may be divided by the fraction of drug free in plasma for that individual to obatin individual estimates of the intrinsic clearance, then these analyzed statistically to obtain a measure of dispersion.

Vdarea is usually calculated with equation 34 .

$$
\text { Vdarea }=\frac{D}{\beta \int_{0}^{\infty} C_{p} d t}=\frac{C l_{p}}{\beta} \quad \mathrm{Eq} .
$$

Substituting from equation 18 for $\beta$ and from equation 33 for $\mathrm{Cl}_{\mathrm{p}}$ into equation 34 , and cancellation of the $k_{f}^{\prime} s$, gives equation 35 .

$$
\mathrm{V}_{\text {darea }}=\left(\frac{\sigma}{\mathrm{f}}\right) \mathrm{V}_{\mathrm{f}}
$$

Equation 35 indicates that in the absence of both plasma protein binding and tissue binding (i.e. $\sigma=f=1$ ), Vaarea $=V_{f}$. However, equation 35 also indicates that Vaarea is not a simple function of $\sigma$, as is clarified below.

Rearrangement of equation 27 gives equation 36 .

$$
A_{f}^{O}=D-A_{T B}^{O}-A_{P B}^{O}
$$

Substituting from equation 27 and 36 into equation 14, and rearrangement yields equation 37

$$
f=1-\frac{\mathrm{A}_{\mathrm{TB}}^{\circ}}{\mathrm{D}}-\frac{\mathrm{A}_{\mathrm{PB}}^{\circ}}{\mathrm{D}}
$$

Substituting for $f$ from equation 37 into equation 35 yields equation 38 .

$$
\text { Varea }=\left[\frac{\sigma}{1-\frac{\mathrm{A}_{\mathrm{TB}}}{\mathrm{D}}-\frac{\mathrm{A}_{\mathrm{PB}}^{\mathrm{O}}}{\mathrm{D}}}\right] \mathrm{V}_{\mathrm{f}} \mathrm{Eq} \text {. }
$$

The portion of equation 38 marked off by square brackets can have a value ranging from much less than unity to much greater than unity, depending upon the relative degrees of plasma protein bind- ing and tissue binding of the drug. When plasma protein binding is very low (i.e. $\sigma \rightarrow 1$ and $\left.\mathrm{AP}_{\mathrm{B}} / \mathrm{D} \rightarrow \mathrm{O}\right)$, and tissue binding is large (i.e. $A_{\mathrm{TB}} / \mathrm{D} \rightarrow 1$ ), then this bracketed portion will be much larger than unity, and $V_{\text {darea }}>V_{f}$. If $\sigma=0.5$ and $\left(\mathrm{APB}+\mathrm{A}_{\mathrm{PB}}\right) / \mathrm{D}=0.5$, then the bracketed portion would be equal to unity and $V_{\text {darea }}=\mathrm{V}_{\mathrm{f}}$. Even for a drug which is both very highly plasma protein bound and tissue bound, Vdarea could be equal to $V_{f}$; for example, if $\sigma=0.02$ and (ATB $\left.+\mathrm{A}_{\mathrm{PB}}\right) / \mathrm{D}=0.98$, then the bracketed portion would be equal to unity. Usually, of course, the bracketed portion would not be equal to unity, hence either $\mathrm{V}_{\text {darea }}>\mathrm{V}_{\mathrm{f}}$ or Vdarea $<\mathrm{V}_{\mathrm{f}}$. Thus, the calculated volume of distribution is not equal, usually, to the volume of distribution of free drug.

The extrapolated volume of distribution, $V_{\text {dext, }}$ is calculated with equation 39 .

$$
\mathrm{v}_{\text {dext }}=\frac{\mathrm{D}}{\mathrm{C}_{\mathrm{p}}^{\mathrm{O}}}
$$

$\mathrm{Eq}$.

Substituting for $\mathrm{C}_{\mathrm{p}}^{\mathrm{O}}$ from equation 30 into equation 39 yields equation 40 .

$$
\mathrm{V}_{\text {dext }}=\left(\frac{\sigma}{\mathrm{f}}\right) \mathrm{V}_{\mathrm{f}}
$$

By comparing the right hand sides of equations 35 and 40 we see that for this model :

$$
\mathrm{V}_{\text {dext }}=\mathrm{V}_{\text {darea }} \quad \mathrm{Eq} \text {. }
$$

Equation 41 is the expected result for this modified "one compartment open model". If there was more than one fluid compartment and/or distribution to some tissues took an appreciable time, than a multicompartmental model would be required, and, in such cases, $V_{\text {dext }}>$ Varea

From equations 14 and 19 it may readily be shown that:

$$
\frac{\sigma}{f}=1+\left(\frac{V_{\mathrm{T}}}{V_{\mathrm{f}}}\right)\left(\frac{\mathrm{C}_{\mathrm{TB}}}{\mathrm{C}_{\mathrm{p}}}\right)
$$

Eq.

Equation 42 indicates that $\sigma \geq f$. Also, rearrangement of equation 34 gives equation 43 . Hence, the model agrees with classical concepts.

$$
\mathrm{Cl}_{\mathrm{p}}=\text { V darea } \beta \quad \mathrm{Eq} \text {. }
$$

Keen (1971) recommended that the volume of distribution be calculated from free drug concentrations, rather than from total drug concentrations. If this is done, then the volume calculated, based on the simple model, is $V_{f} / f$. The same result would be obtained by dividing the volumes, Vdext and Vdarea, estimated from total drug concentrations, by $\sigma$. It should be noted that such volumes 
are still dependent upon relative degrees of plasma protein binding and tissue binding, as pointed out by keen (1971). The product of the apparent elimination rate constant, $\beta$, and such a volume (estimated from free drug concentrations) is, by use of equation 18, equal to the intrinsic clearance of free drug, as indicated by equation 44 .

$$
\begin{aligned}
\text { Intrinsic clearance } & =\left(\frac{V_{f}}{f}\right)\left(f k_{f}\right) \\
& =V_{f} k_{f}
\end{aligned}
$$

If there are multicompartmental pharmacokinetics, then the volume calculated from free drug concentrations should be the modified Vdarea, rather than Vdext, unless, as is sometimes the case, the two volumes are essentially identical.

Estimation of $V_{f}$ and $A_{T B} / A_{f}$ - Substituting from equation 20 into equation 14 yields equation 45 . The latter is also obtained by rearranging equation 21 .

$$
f=\frac{1}{\frac{1}{\sigma}+\frac{\mathrm{A}_{\mathrm{TB}}}{\mathrm{A}_{\mathrm{f}}}}
$$

Substituting from equation 45 into equation 40 and simplifying gives equatio 46 .

$$
v_{\text {dext }}=\left[1+\sigma\left(\frac{A_{T B}}{A_{f}}\right)\right] V_{f} \quad \mathrm{Eq} .
$$

Equation 46 indicates that a plot of $V_{\text {dext }}$ versus $\sigma$ will be linear with intercept equal to $V_{f}$, and slope equal to ( $\mathrm{A}_{\mathrm{TB}} / \mathrm{A}_{\mathrm{f}}$ ) $\mathrm{V}_{\mathrm{f}}$. Hence, $\mathrm{A}_{\mathrm{TB}} / \mathrm{A}_{\mathrm{f}}$ is obtained with equation 47 .

$$
\frac{\mathrm{A}_{\mathrm{TB}}}{\mathrm{A}_{\mathrm{f}}}=\frac{\text { Slope }}{\text { Intercept }}=\frac{\left(\mathrm{A}_{\mathrm{TB}} / \mathrm{A}_{\mathrm{f}}\right) \mathrm{V}_{\mathrm{f}}}{V_{\mathrm{f}}}
$$

Eq. (47)

Estimation of $k_{f}$ and $f$ - Since $V_{f}$ is known (see above) and the intrinsic clearance, $V_{f} k_{f}$, is known by dividing $C l_{p}$ by $\sigma$ (equation 33), then an estimate of $\mathrm{k}_{f}$ is obtained from equation 48 .

$$
\mathrm{k}_{\mathrm{f}}=\frac{\text { Intrinsic Clearance }}{\mathrm{V}_{\mathrm{f}}}=\frac{\mathrm{V}_{\mathrm{f}} \mathrm{k}_{\mathrm{f}}}{\mathrm{V}_{\mathrm{f}}}
$$

Now that $k_{f}$ and $\beta$ are known, then " $f$ " may be estimated by rearranging equation 18 to give equation 49 .

$$
\mathrm{f}=\frac{\beta}{\mathrm{k}_{\mathrm{f}}}
$$$$
\mathrm{Eq}
$$

Estimation of $A_{T B}^{O}$ - If we write equation 5 for the zero time condition, then equation 50 is obtained. Also, since binding is linear, equation 51 holds.

$$
A_{I}^{O}=V_{f} C_{f}^{O}
$$

Eq. (5O)

$$
\frac{\mathrm{A}_{\mathrm{TB}}}{\mathrm{A}_{\mathrm{I}}}=\frac{\mathrm{A}_{\mathrm{TB}}}{\mathrm{A}_{\mathrm{f}}^{\circ}}
$$

Eq.

Since the ratio $\mathrm{ATH}_{\mathrm{TB}} / \mathrm{A}_{\mathrm{f}}$ is known from equations 47 and 51 , and, $A_{f}^{O}$ is known from equation 50, then ATB is obtained. with equation 52 .

$$
\mathrm{A}_{\mathrm{TB}}^{\circ}=\frac{\mathrm{A}_{\mathrm{TB}}^{\mathrm{O}} / \mathrm{A}_{\mathrm{f}}^{\circ}}{\mathrm{V}_{\mathrm{f}} \mathrm{C}_{\mathrm{f}}^{\mathrm{O}}}
$$

Eq.

\section{S IMULATIONS}

Simulation with equation 22 - A plot of the apparent elimination rate constant, $\beta$, versus the fraction free in plasma, $\sigma$, does not separate the variables as may be seen from equation 22. Even in those cases where the ratio $A_{T B} / A_{f}$ is constant, while $\sigma$ varies, plots of $\beta$ versus $\sigma$ will be curved as may be seen in Figure 1. The greater the value of the ratio $A_{T B} / A_{f}$, the greater the curvature. For low values of $A_{T B} / A_{f}$, the plots are nearly linear. In real life, one would expect $\mathrm{A}_{\mathrm{TB}} / \mathrm{A}_{\mathrm{f}}$ to vary, and not be constant, from one individual to the next. This would cause scatter on the plots of $\beta$ versus $\sigma$. Evaluation of such "scattered data" by linear regression analysis, would lead to an apparent positive intercept on the ordinate. But, the intercept and slope values obtained from such plots would have no physical significance. Thus, correlations of $\beta$ with $\sigma$ are not recommended. This would also apply to any transformation, such as half-life.

Simulation with equation 46 - Two sets of data were generated by letting $\mathrm{ATB}_{\mathrm{TB}} / \mathrm{A}_{\mathrm{f}}$ equal 10 and 50 , then varying $\sigma$ over the range 0.004 to 0.02 . For a given value of $\sigma$, the value of "f" was calculated with equation 45 , then the corresponding value of $\sigma / f$, equivalent to $V_{\text {dext }} / V_{f}$, was calculated using equation 40. Results are shown in Figure 2. Extrapolation of the linear plots to the ordinate yielded a value of unity, equal to $V_{f} / V_{f}$ in this case. The slopes of the lines are the same as the assigned values of $\mathrm{A}_{\mathrm{TB}} / \mathrm{A}_{f}$, namely 50 and 10 . Suppose the value of $V_{f}$ was $0.61 / \mathrm{kg}$. Then, using the value of $A_{T B} / A_{f}=50$, the slope of the $V_{\text {dext }}$ versus $\sigma$ plot would be 30, and the intercept would be 0.6 . Hence, the calculated value of $A_{T B} / A_{f}$ would be slope/intercept $=30 / 0.6=50$. If there was considerable scatter on a plot of Vaext versus $\sigma$, this would indicate variation in the ratio $\mathrm{A}_{\mathrm{TB}} / \mathrm{A}_{\mathrm{f}}$ from one individual to the next.

\section{DISCUSSION}

The simple model employed incorporated linear tissue binding, linear plasma protein binding, and first order elimination 


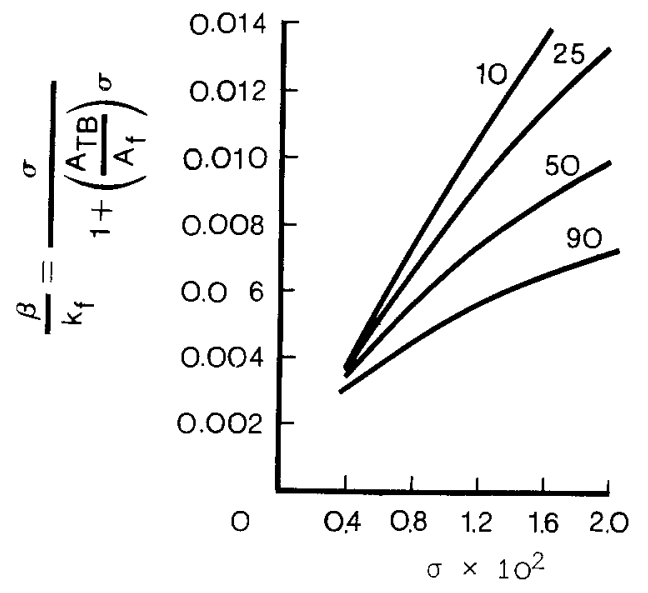

Fig. 1. Results of simulations with equation 22 (see text). Indicates curvature obtained when apparent elimination rate constant plotted versus fraction free in plasma. Numbers on curves refer to assigned values of the ratio $\mathrm{A}_{\mathrm{BT}} / \mathrm{A}_{f}$

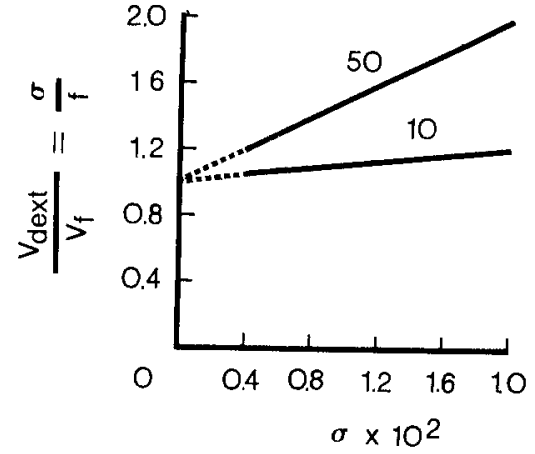

Fig. 2. Results of simulations with equation 40 (see text). Numbers on lines refer to assigned values of the ratio $A_{T B} / A_{f}$ of free (unbound) drug, hence any conclusions are limited to real systems with these properties. The most important equations derived are $18,22,33,40$, and 46 through 52, which require equations $14,19,31,34$ and 39 for interpretation.

With respect to inter-individual comparisons, the model suggests the following:

(1) Dividing the plasma clearance, $\mathrm{Cl}_{\mathrm{P}}$, (estimated from total plasma concentrations) by the fraction of drug free in plasma, $\sigma$, will provide estimate of the intrinsic clearance of free drug, $V_{f} k_{f}$. The values obtained from a panel of subjects or patients, or a group of animals, may then be treated statistically to obtain a mean and some measure of dispersion, such as the coefficient of variation. Alternatively, one could plot $\mathrm{Cl}_{\mathrm{p}}$ versus $\sigma$ and the slope of the least squares linear regression line would be an estimate of $V_{f} k_{f}$ for the population.

(2) A plot of the extrapolated volume of distribution, Vdext, versus fraction free in plasma, $\sigma$, has an intercept equal to $V_{f}$ and a slope equal to $\left(A_{T B} / A_{f}\right) V_{f}$, hence the ratio $A_{T B} / A_{f}$ is obtained by dividing the slope by the intercept. Once $V_{f}$ and $A_{T B} / A_{f}$ are known, then $k_{f}, f$, and ATB are readily obtained, providing there is not much variation in $A_{T B} / A_{f}$.

(3) The apparent elimination rate constant, $\beta$, is equivalent to the product of the intrinsic elimination rate constant for free drug, $\mathrm{k}_{\mathrm{f}}$, and the fraction of the total drug in the body which is free, symbolized by $f$. It should be noted that $\beta$ is not equal to $\sigma \mathrm{k}_{f}$, unless there is absolutely no tissue binding. When $B$ is plotted versus $\sigma$, the variables are not separated, and the plot will have a gentle curvature. If, also, $\mathrm{ATB}_{\mathrm{TB}} / \mathrm{A}_{\mathrm{f}}$ varies appreciably from one individual to the next, then there will be considerable scatter on the $\beta$ versus $\sigma$ plots. These types of plots are not recommended. Since the binding of drugs to plasma proteins is extremely rapid (Keen, 1971) and the binding of some drugs to tissues is also extremely rapid (see wagner, 1973 for diphenhydramine in the rat; and Benya and Wagner, 1975 for warfarin in the rat), one might expect the model to hold for low doses in some cases. It should be noted that if one derives equations for a similar model, but with several different types of tissues, the same general form for equation 17 is obtained, except that there are additional terms in the denominator for each type of tissue (see Wagner, 1971).

The equations derived in this article and the conclusions reached differ appreciably from some of those of Keen (1971), Coffey (1972), Krüger-Thiemer (1966 and 1968), Levy and Yacobi (1974) and Yacobi and Levy (1975). The reason for the differences is the inclusion of both tissue binding and plasma protein binding in the model and derivations in the present article, whereas previous authors cited were principally concerned only with plasma protein binding. It is hoped that this article will aid in obtaining additional pharmacokinetic information when a drug is administered by bolus intravenous injection to either a panel of subjects or patients or to a group of animals of one species. Also, it discloses some possible pitfalls in the analysis of such pharmacokinetic data. 


\section{REFERENCES}

Albert, K.S., Hallmark, M.R., Sakmar, E., Weidler, D.J., Wagner, J.G.: Pharmacokinetics of diphenhydramine in man. J. Pharmacokin. Biopharm. 3, 159 - 170 (1975)

Anton, A.H., Solomon, H.M.: Drug-protein binding. Ann. N. Y. Acad. Sci. 226, 1 - 362 (1973)

Benya, T.J., Wagner, J.G.: Rapid equilibration of warfarin between rat tissue and plasma. J. Pharmacokin. Biopharm. 3, 237 - 255 (1975)

Bischoff, K.B., Dedrick, R.L.: Thiopental pharmacokinetics. J. pharm. Sci. 57, 1346 - 1351 (1968)

Coffey, J.J.: Effects of protein binding of drugs on areas under plasma concentration-time curves. J. pharm. Sci. 61, 138 - 139 (1972)

DiSanto, A.R.: A new nonlinear pharmacokinetic model with specific application to methylene blue. Ph. D. dissertation, The University of Michigan 1971

Garrett, E.R.: Relations and conversions among variously referenced apparent volumes of distribution of the central compartment. Abstracts of papers presented at the 13th national meeting of the A. Ph. A. Academy of Pharmaceutical Sciences, Chicago, Illinois, November 5 - 9, Vol. 2, No. 2, pp. $174-175$, 1972

Hermann, J.J.: Physical model approach to the uptake and release of ouabain and digitoxin by human erythrocytes. Ph. D. dissertation, The University of Michigan, pp. 179, 1975

Keen, P.: Effect of binding to plasma proteins on the distribution, activity and elimination of drugs. In: Handbuch der experimentellen Pharmakologie 28, 213 - 233, part 1, Berlin: Springer-Verlag 1971

Krüger-Thiemer, E.: Solution of pharmacological problems by computers. 6. Models for the effect of protein-binding on the clearance of drugs. Arzneimittel-Forsch. 16, 1431 - 1442 (1966)

Krüger-Thiemer, E.: Pharmacokinetics and doseconcentration relationships. Proc. IIIrd Intern. Pharmacol. Meeting 7, 63 - 113 (1968)

Krüger-Thiemer, E., Diller, W., Bunger, P.: Pharmacokinetic models regarding protein binding of drugs. Antimicrob. Agents Chemother. 1965 183 - 191 (1966)

Levy, G., Yacobi, A.: Effect of plasma protein binding on elimination of warfarin. J. pharm. sci. 63, $805-806$ (1974)

Martin, B.K.: Potential effect of the plasma proteins on drug distribution. Nature 207, 274 - 276 (1965)

Wagner, J.G.: Biopharmaceutics and relevant pharmacokinetics. pp. 302 - 317. Hamilton, Illinois: Drug Intelligence Publications, Inc. 1971

Wagner, J.G.: A modern view of pharmacokinetics. J. Pharmacokin. Biopharm. 1, 363 - 401 (1973)

Wagner, J.G.: Fundamentals of clinical pharmacokinetics. pp. $24-29 ; 271-283 ; 381-382$. Hamilton, Illinois: Drug Intelligence Publications, Inc. 1975

Yacobi, A., Levy, G.: Comparative pharmacokinetics of coumarin anticoagulants. XIV: Relationship between protein binding, distribution, and elimination kinetics of warfarin in rats. J. pharm. Sci. 64, $1660-1664$ (1975)

Dr. J.G. Wagner

Upjohn Center for Clinical Pharmacology

The University of Michigan

Ann Arbor, Michigan 48109

USA 